\title{
Can Anthropometric Variables and Maturation Predict the Playing Position in Youth Basketball Players?
}

\author{
by \\ Karol Gryko ${ }^{1}$, Petr Stastny², Anna Kopiczko ${ }^{3}$, Kazimierz Mikołajec ${ }^{4}$, Ondrej Pecha ${ }^{5}$, \\ Krzysztof Perkowski ${ }^{1}$
}

\begin{abstract}
Anthropometric diagnoses predict the most appropriate on-court position for a certain player and are important in the long-term planning of basketball training programs. This study provides anthropometric characteristics and body composition profiles of Polish youth national team players (U-14, U-15, U-16 and U-18). The aim of this research was to determine the somatic characteristics of basketball players regarding particular on-court positions. The sample population consisted of 109 elite basketball players, who played in national teams in four age categories: U-14, U-16, U-18 U-20. An analysis of the obtained results revealed differences between the younger (U-14, $U-15$ and $U-16)$ and older groups (U-18 and U-20) in terms of length, width and circumference measurements and body mass (3.6-9.3\%), as well as subcutaneous fat measured by the skinfold thickness method (14.3-33.7\%). ANCOVA with maturity offset as the covariate variable showed differences in body height $\left(p<0.05, R^{2}=0.74\right)$ and the arm span $\left(p<0.05, R^{2}=0.87\right)$ between each playing position; the somatic measurements were greater for centers than for forwards and guards, and the measurements were greater for forwards than for guards. The somatic feature measurements also increased linearly with age. We can conclude that the arm span and body height are two major somatic factors that can predict center and guard playing positions for national team basketball players in all age categories from U-14 to U-20.
\end{abstract}

Key words: anthropometric indicators, somatotype, peak height velocity, professional sport, selection, basketball players.

\section{Introduction}

Basketball is one of the most popular sports in the world. It is a team sport in which the final success of the team largely depends on the technical, motor, tactical, physiological and mental preparation of the team members (Erčulj and Štrumbelj, 2015; Escalante et al., 2010; García et al., 2013; Mikołajec et al., 2012). One of the skills that is essential to a successful performance in basketball is the ability to execute effective movements with physical pressure from the opponent (Fruchart et al., 2010; Kostopoulos,
2015), which requires each player to display a high level of specific anthropometric indicators (Koley and Singh, 2010; Muratovic et al., 2014), general fitness (Drinkwater et al., 2008; Jakovljević et al., 2011) and physical capacity (Czuba et al., 2013; Kollos and Tache, 2013).

Basketball players cover a distance of 4.5 to $5 \mathrm{~km}$ during a 40 -min game while performing high-intensity, dynamic, multidirectional movements, such as sprinting, dribbling, jumping, turning and screening (Crisafulli et al., 2002; Meckell et al., 2009). Due to the specific demands

1 - Department of Athletics and Team Sport Games, Józef Piłsudski University of Physical Education, Warsaw, Poland.

2 - Faculty of Physical Education and Sport, Prague, Department of Sport Games, Charles University, Czech Republic.

3 - Department of Anthropology and Health Promotion, Józef Pitsudski University of Physical Education, Warsaw, Poland.

4 - Department of Team Sport Games, Jerzy Kukuczka Academy of Physical Education, Katowice, Poland, Czech Academy of Science, Czech Republic.

5 - Technology Centre of the Czech Academy of Sciences. 
of this sport, the key factors that will predict the efficiency of a team during a game include the recruitment and selection of players. An adequate anthropometric diagnosis is fundamental for ensuring the effective recruitment of basketball players. This diagnosis also indicates whether a player will be suitable for participating in elitelevel competitions (Hoare, 2000; Petrovic et al., 2013). The somatic features and body build profiles of successful basketball players help in predicting the results (Bayios et al., 2006; Ostojic et al., 2006).

When assessing somatic structures and predicting the development of each somatic feature, one should consider that during puberty, rapid increases in body size and body mass as well as an improvement in physical fitness are observed, which are mainly caused by hormonal and maturational changes. However, the maturation process does not occur at the same chronological age (CA) for all individuals - the range from the $10^{\text {th }}$ to the $90^{\text {th }}$ percentiles of ages at peak growth spans approximately 4.5 years (Torres-Unda et al., 2016). The number of years an individual is from their age at peak height velocity (YPHV) is a good indicator of maturity of boys aged between 12 and 16 years and can be calculated using their CA and simple anthropometric measurements (Mirwald et al., 2002). Biological maturation is significantly associated with the growth and functional capacity of adolescents, which is the reason it is possible for boys of the same age to show significant differences in performance (Malina et al., 2005).

Recently, researchers have become progressively interested in the anthropometric and morphological indicators and the body build profiles of both youth (Drinkwater et al., 2007; Gomes et al., 2015; Jakovljevic et al., 2011; Petrovic et al., 2013) and professional athletes (Ostojic et al., 2006; Vaquera et al., 2015). These researchers look for models of somatic traits that will likely improve players' competitiveness (Kica, 2012; Ochoa et al., 2014).

Measurements of individuals' linear dimensions, body diameters, body mass and skinfolds, which are considered the key components of a somatic build profile of an elite player, have been monitored (Vaquera et al., 2015). These measurements are critical in selecting players for each position on the court (Abdelkrim et al., 2010; Jakovljevic et al., 2011). Tall players with significant muscle mass and long limbs play as centers and are placed near the basket, and shorter players with lighter frames are preferred as guards and play mostly on the perimeter, away from the basket (Gryko et al., 2018, Pojskic et al., 2014; Sallet et al., 2005). Therefore, somatic features constitute an important and reliable indicator of basketball players' performance (Drinkwater et al., 2008).

It has been suggested that young basketball players who are tall and have a large body mass and long limbs can achieve a high performance level and participate in professional competitions when they are older. Moreover, at a professional level, these players have high oncourt effectiveness (Sisodiya and Yadaf, 2010). The body height, body mass and body composition of youth and professional basketball players are not the only variables to be considered in research. There are scientific reports that have analysed other specific variables (Gerodimos et al., 2005; Ostojic et al., 2006), but these reports have not provided information on a wide spectrum of anthropometric features (e.g., dactylion III and tibial landmarks). Therefore, the aim of this study was to present a comprehensive view of the anthropometric characteristics and compare the body build profiles of basketball players from the Polish national youth basketball teams (U-14, U-15, U-16, U-18 and U-20). The second objective was to determine whether there was a somatic characteristic of individuals who played specific positions that predisposed them to play those positions throughout all observed categories.

\section{Methods}

The study evaluated 109 top Polish players from the men's national youth basketball teams. All players were of Polish ancestry and Caucasian race. The first group $(n=32)$ included basketball players from the U-14 Poland national basketball team (age: $14.2 \pm 0.2$ years; training experience: $3.9 \pm 1.3$ years). The second group ( $n=$ 24) was composed of members of the U-15 national team (age: $14.9 \pm 0.2$ years; training experience: $5.1 \pm 1.3$ years). The third group ( $n=$ 21) that participated in the research were members of the U-16 team (age: $15.8 \pm 0.3$ years; 
training experience: $5.7 \pm 1.2$ years), another group consisted of members of the U-18 team $(n=17$; age: $17.7 \pm 0.5$ years; training experience: $8.4 \pm 0.9$ years), and the last group included members of the U-20 team ( $n=15$; age: $19.6 \pm 0.6$ years; training experience: $9.2 \pm 0.9$ years).

All of the participants were informed about the aims, benefits and procedures of the research project, as well as the possibility to withdraw from the study at any moment without providing an explanation. The inclusion criterion was the written consent of each participant, and the exclusion criteria included contraindications for the basic anthropometric measurements. The study was approved by the Senate Research Ethics Committee of the Academy of Physical Education in Warsaw, Poland. The project was executed in accordance with the principles specified in the Declaration of Helsinki (World Medical Association [WMA], 2013).

The main research method consisted of anthropometric measurements under standardised conditions. All measurements were taken at the first training camp at the beginning of the preparatory period of the European Championships. The measurements were taken by an anthropometry expert according to the standards proposed by the International Society for the Advancement of Kinanthropometry (ISAK) (Marfell-Jones et al., 2012).

The somatotype was calculated according to the Heath-Carter method (Carter and Heath, 1990) using the Somatotype 1.2.6 computer program (MER Goulding Software Development, Geeveston, Australia). Body mass and body fat (BF) percentages were determined with the bioelectrical impedance analysis (BIA) method using a Jawon Medical X-SCAN PLUS 970 analyser (Seoul, South Korea). The following variables were recorded: age [years], basketball experience [years], body mass $[\mathrm{kg}]$, body height $[\mathrm{cm}]$, sitting height $[\mathrm{cm}]$, arm span $[\mathrm{cm}]$ and the distance to the suprasternale (sst), acromion (a), dactylion III (da III), tibiale (ti) and the symphysion (sy) anthropometric landmarks (0.1 $\mathrm{cm}$, with the GPM Anthropometer, previous brand name Siber Hegner, Switzerland); additional measurements included chest depth, shoulder width, chest width, pelvic width, hip width, elbow breadth, knee breadth, wrist breadth, palm breadth, arm length, forearm length, palm length, lower leg length and foot length $(\mathrm{cm}$, with the GPM Large and Small Spreading Calliper, Switzerland); circumferences of the following areas of the body were also recorded: relaxed arm, flexed arm, relaxed chest, chest at full inspiration/expiration, waist, hip, thigh and calf $(\mathrm{cm}$, with Holtain's Anthropometric Tape, UK); and finally, skinfolds of the following areas of the body were also recorded: triceps, biceps, subscapular, pectoral, suprailiac, supraspinale, abdominal, kneecap and calf $(\mathrm{mm}$, with the Harpenden Skinfold Calliper, British Indicators, West Sussex, UK).

The results of the length of the lower limb were obtained based on the measurements of the symphysion anthropometric landmark, and indirect measurements were used to obtain the measurements for the upper limbs (a-da III), body trunk (sst-sy) and thigh (sy-ti). The following equation was used to assess the level of maturity of youth players: YPHV (years from age at peak height velocity) $=-9.236+0.0002708$ leg length and sitting height interaction -0.001663 age and leg length interaction +0.007216 age and sitting height interaction +0.02292 body mass divided by height, where $\mathrm{R}^{2}=0.891$ and SEE $=0.592$ (Mirwald et al., 2002). Age at peak height velocity was then calculated as follows: CA (chronological age) YPHV.

\section{Statistics}

Analysis of the quantitative data was based on the following indices: the arithmetic mean, standard deviation (SD), highest and lowest values in the set (max. and min., respectively), median and standard error of the mean (SEM).

The Shapiro-Wilk test was applied to examine the distribution of the results. The conducted analysis confirmed the assumption of normality of the distribution. The data were tested for the equality of variances using the Levene's test. For equal variances, the level of significance of the differences in each anthropometric characteristic between the U14, U15, U16, U17, and U18 national teams was evaluated using analysis of variance (ANOVA) and the post hoc Tukey test for unequal group sizes. Effect size was calculated as eta-squared $\left(\eta^{2}\right)$ and $<0.10$ indicated a small effect, $0.10-0.40$ indicated a medium effect, and $<0.40$ indicated a large effect (Grissom and Kim, 2012). Statistical significance of the 
differences was assumed when $p<0.05$.

The collected data of the anthropometric characteristics of the members of the national teams (from the U-14 group to the U-20 group) were also presented in the form of somatocharts and interactive scatter plots, which allowed each measured variable to be displayed with the covariance of calendar or biological age and grouped by position or age category (https://onpecha.cz/basket/national.html). The one-way ANCOVA with maturity offset as a covariate variable was used to estimate the differences between playing positions across all national team members. All of the calculations and analyses were performed using STATISTICA software (v.12, StatSoft, USA).

\section{Results}

The characteristics of players from the national teams, including the distances to the anthropometric landmarks, are presented in Table 1. Analysis of differences in somatic features between the members of the Poland national teams conducted with the post hoc Tukey test revealed that the sitting height $(F=6.72, p=0.002$, $\left.\eta^{2}=0.15\right)$ of $U-16$ players was significantly greater than the sitting height of players from U-14 and U-15 national teams (by $4.4 \%$ and $3.6 \%$, respectively). Players from the U-16 national team also had larger body mass $\left(F=5.16, p=0.027, \eta^{2}=\right.$ 0.09 ) and distances to the suprasternale landmark $\left(F=6.07, p=0.017, \eta^{2}=0.11\right.$ ) (by $9.3 \%$ and $2.8 \%$, respectively) than players from the U-14 national team. On the other hand, lower BF values were observed in the U-16 national team than in U-14 (by $3 \% ; F=7.68, p=0.008, \eta^{2}=0.13$ ) and U-15 teams (by $3.9 \% ; F=14.69, p=0.001, \eta^{2}=0.26$ ).

In addition, a significantly lower percentage of the endomorphic component (by $19.5 \% ; F=7.73, p=0.008, \eta^{2}=0.15$ ) was noted in U-16 basketball players than in U-15 players (Figure 1). The mean somatotype of basketball players was 2.54-3.85-3.82 (values for endomorphy $2.54 \pm 0.82$, mesomorphy $3.85 \pm 1.03$ and ectomorphy $3.82 \pm 1.0$ ). The largest diversity was observed in endomorphy (ranging from 1.37 to 5.84), mesomorphy (ranging from 1.11 to 7.32 ) and ectomorphy (ranging from 0.81 to 6.88 ).

The analysis of differences in the distance to the tibiale landmark between basketball players from U-20 and U-18 teams (Table 1) showed significantly $\left(F=9.59, p=0.004, \eta^{2}=0.24\right)$ higher values in the U-20 team (by 5.4\%). Likewise, the distance to the dactylion III landmark was longer by $4.1 \%\left(F=6.06, p=0.020, \eta^{2}=0.17\right)$ in U-20 players than in U-18 players.

The analysis of results concerning the width and breadth characteristics (Table 2) showed that the members of the U-16 team displayed significantly greater values for the shoulder width (by $5 \%, F=6.17, p=0.003, \eta^{2}=$ 0.14 ), chest width (by $5.2 \%, F=4.21, p=0.018, \eta^{2}=$ 0.10 ), hip width (by $4.6 \%, F=3.90, p=0.024, \eta^{2}=$ 0.10 ), wrist breadth (by $3.5 \%, F=4.21, p=0.018, \eta^{2}$ $=0.10$ ) and chest depth (by 7.6\%, $F=4.38, p=$ $0.016, \eta^{2}=0.11$ ) compared to the members of the U-14 national team. In comparison to U-15 players, basketball players from the U-16 national team also had broader shoulders (3.2\%). However, players from the U-15 team had broader chests (by $3.8 \%$ ) and elbows (by $2.7 \%, F=$ $4.32, p=0.042, \eta^{2}=0.07$ ) compared to players from the U-14 team. Furthermore, the chest widths of U-20 team members were wider compared to those of U-18 team members (by $4.9 \%, F=5.60, p=$ $0.025, \eta^{2}=0.16$ ). There were no statistically significant differences in other characteristics of athletes when comparing the two national teams with the oldest age groups.

Similar results were observed in the differences in body circumferences (Table 3); basketball players from the U-16 team had longer flexed arm circumferences (by 6.8\%, $F=6.18, p=$ $0.003, \eta^{2}=0.14$ ), thigh circumferences (by $8.1 \%, F=$ 7.60, $\left.p=0.001, \quad \eta^{2}=0.17\right)$, relaxed arm circumferences (by 6\%, $F=4.23, p=0.018, \eta^{2}=$ 0.10 ), chest circumferences at full inspiration (by $\left.4.7 \%, F=4.25, p=0.018, \eta^{2}=0.10\right)$, relaxed chest circumferences (by 4.7\%, $F=3.46, p=0.037, \eta^{2}=$ 0.09 ), chest circumferences at full expiration (by $\left.4 \%, \quad F=5.43, p=0.024, \eta^{2}=0.10\right)$, waist circumferences (by 3.9\%, $F=4.36, p=0.042, \eta^{2}=$ 0.08 ) and hip circumferences (by $3.8 \%, F=5.12, p=$ $0.028, \eta^{2}=0.09$ ) than players from the U-14 team. Additionally, in comparison with players from the U-15 team, players from the U-16 team had significantly longer thigh circumferences (by $5.6 \%)$.

On the other hand, when compared to players from the U-18 team, the members of the U-20 national team showed longer relaxed arm circumferences (by $7 \%, F=12.25, p=0.001, \eta^{2}=$ 
0.29), flexed arm circumferences (by $8.1 \%, F=$ 13.41, $\left.p=0.001, \eta^{2}=0.31\right)$, relaxed chest circumferences (by 6.2\%, $F=8.98, p=0.005, \eta^{2}=$ 0.23), chest circumferences at full inspiration/expiration, waist circumferences and hip circumferences (ranging from 4 to $6 \%, p<$ 0.05).

Analysis of the subcutaneous fat results showed significantly thicker calf skinfolds (by $\left.33.7 \%, F=4.77, p=0.011, \eta^{2}=0.11\right)$ and subscapular skinfolds (by $14.3 \%, F=3.34, p=$ $\left.0.040, \eta^{2}=0.08\right)$ of the U-15 team compared to the U-14 team (Figure 2). Moreover, in the study, thinner triceps skinfolds (by 27.2\%, $F=4.92, p=$ $0.009, \eta^{2}=0.12$ ), pectoral skinfolds (by $28.8 \%, F=$ $7.45, p=0.009, \eta^{2}=0.15$ ), suprailiac skinfolds (by $\left.32.2 \%, F=4.80, p=0.034, \eta^{2}=0.10\right)$, abdominal skinfolds (by 36.8\%, $F=6.64, p=0.013, \eta^{2}=0.13$ ) and calf skinfolds (28.9\%) were observed in the U15 team compared to the U-16 team. On the other hand, no significant differences were observed between the U-18 and U-20 teams.

The body build profiles of all basketball players from the U-14 to U-18 national teams that were developed by means of standardisation to the group of U-20 players are presented in Table 3. The profiles show that most significant differences in the characteristics of body build among young national team members, compared to the oldest players, were in the following variables: flexed arm circumference (from -1.23 to $-3.00 S D$ ), relaxed arm circumference (from -0.95 to $-2.50 S D$ ), thigh circumference (from -0.44 to $1.90 S D$ ), shoulder width (from -0.50 to $-1.70 S D$ ), body mass (from -0.68 to $-1.68 S D$ ) and body height (from -0.52 to $-1.66 S D$ ); these differences reflect the stockiness of the body build of players in the U-20 category.

The one-way ANCOVA analyses with maturity offset as a covariate variable showed that body height $\left(\mathrm{F}_{5}, 108=146, p<0.001, \mathrm{R}^{2}=0.87\right)$ and the arm spam $\left(\mathrm{F}_{5,108}=146, p<0.001, \mathrm{R}^{2}=0.75\right)$ differed between playing positions throughout all age categories (Table 4); the measurements of centers were greater than those of forwards and guards, and the measurements of forwards were greater than those of guards.

\section{Discussion}

Sisodiya and Yadaf (2010) found that agerelated physical development resulting in changes in body build (increases in body height, body mass and length of individual body parts) is critical to the selection and recruitment of basketball players for older age categories and is one of the factors that determines an individual's highest possible skill level in basketball, a sport that prefers tall and heavy players with a strong body build. This observation was consistent with the findings of our study. Our study provides clear evidence that the positions listed in descending order according to players' body height and arm span are centers, forwards and guards.

Contemporary demands of basketball require centers and forwards to be tall and have long arm spans, which are particularly useful characteristics when individuals maintain contact with the opponent, retrieve both offensive and defensive rebounds, block the ball, and screen the defenders. For guards, a large arm span can be beneficial when the player deflects and steals the ball, and when the player is on the offense, it can be beneficial when the player changes directions with the ball and can improve the quality of his or her passes.

Another factor that supports adequate recruitment of basketball players or the selection of the appropriate on-court position, is the BMI (Vaquera et al., 2015). Research conducted on Spanish basketball players revealed a greater BMI in older players when compared to younger players, which is consistent with our findings (from 21.0 in the U-14 team to 23.8 in the U-20 team). This increase in the BMI is due to the ongoing growth process in young players and building of muscle mass in older players (Sallet et al., 2005; Vaquera et al., 2015).

Late-maturing individuals should be sought in the selection process, as these individuals obtain maximum lengths of body variables and appropriate ratios of body tissue components for individual playing positions at the very last stages of youth training. It is therefore important to avoid the common practice in which coaches, at the initial stages of training, focus on the development of early-maturing players to achieve the best possible sports results as quickly as possible. The consequence of using such an approach is early specialisation in positions, which may lead to restrictions in the development of technical and tactical skills of the player in the later stages of training. 
Table 1

Characteristics of players from national teams, including distances to anthropometric landmarks.

\begin{tabular}{|c|c|c|c|c|c|c|}
\hline Variables & & $\begin{array}{c}\mathrm{U}-14 \\
(n=32)\end{array}$ & $\begin{array}{c}\text { U-15 } \\
(n=24)\end{array}$ & $\begin{array}{c}\mathrm{U}-16 \\
(n=21)\end{array}$ & $\begin{array}{c}\mathrm{U}-18 \\
(n=17)\end{array}$ & $\begin{array}{c}\mathrm{U}-20 \\
(n=15)\end{array}$ \\
\hline \multirow{3}{*}{ Age [years] } & a & $14.2 \pm 0.2$ & $14.9 \pm 0.2$ & $15.8 \pm 0.3$ & $17.7 \pm 0.5$ & $19.6 \pm 0.6$ \\
\hline & $\mathrm{b}$ & $13.3-14.5$ & $14.4-15.1$ & $15.2-16.1$ & $16.5-18.3$ & $18.5-20.3$ \\
\hline & c & 14.3 & 14.9 & 15.8 & 17.8 & 19.8 \\
\hline \multirow{3}{*}{$\begin{array}{l}\text { Basketball } \\
\text { experience [years] }\end{array}$} & a & $3.9 \pm 1.3$ & $5.1 \pm 1.3$ & $5.7 \pm 1.2$ & $8.4 \pm 0.9$ & $9.2 \pm 0.9$ \\
\hline & $\mathrm{b}$ & $1.0-7.5$ & $2.5-7.0$ & $3.5-8.2$ & $6.5-10.1$ & 7.3-11.1 \\
\hline & c & 3.9 & 5.4 & 5.7 & 8.2 & 9.1 \\
\hline \multirow{3}{*}{ Body height [cm] } & a & $186.6 \pm 7.3$ & $187.0 \pm 9.1$ & $190.8 \pm 7.0$ & $193.9 \pm 8.1$ & $197.2 \pm 6.4$ \\
\hline & $\mathrm{b}$ & $173.5-197.9$ & $173.2-205.1$ & $173.5-204.6$ & $182.1-212.0$ & $186.7-207.6$ \\
\hline & c & 186.3 & 189.3 & 192.2 & 191.9 & 198 \\
\hline \multirow{3}{*}{ Body mass $[\mathrm{kg}]$} & a & $73.3 \pm 11.9^{\#}$ & $77.3 \pm 11.3$ & $80.1 \pm 8.0^{\#}$ & $85.0 \pm 12.4$ & $93.0 \pm 11.7$ \\
\hline & $\mathrm{b}$ & $56.2-113.7$ & $55.0-96.6$ & $64.4-93.3$ & 70.9-118.9 & $76.3-119.2$ \\
\hline & c & 72.3 & 77.5 & 81.8 & 81.5 & 88.2 \\
\hline \multirow{3}{*}{ Body fat [\%] } & a & $16,5 \pm 4,5$ \#\# & $17,4 \pm 3,9^{\wedge \wedge \wedge}$ & $13,5 \pm 2,4$ ^^^ \#\# & $12,1 \pm 3,7$ & $13,1 \pm 4,1$ \\
\hline & $\mathrm{b}$ & $9,5-29,3$ & $10,2-27,6$ & $9,2-19,0$ & $7,3-20,7$ & $8,7-25,1$ \\
\hline & c & 16,5 & 17,6 & 13,5 & 11,9 & 12,6 \\
\hline \multirow{3}{*}{ BMI $\left[\mathrm{kg} / \mathrm{m}^{2}\right]$} & a & $21,0 \pm 2,4$ & $22,0 \pm 2,3$ & $22,0 \pm 1,4$ & $22,5 \pm 1,6$ & $23,8 \pm 2,1$ \\
\hline & $\mathrm{b}$ & $17,7-29,9$ & $18,1-26,9$ & $19,0-24,4$ & $20,7-26,5$ & $21,6-29,2$ \\
\hline & c & 20,7 & 21,8 & 22,1 & 22,1 & 23,8 \\
\hline \multirow{3}{*}{ Arm span $[\mathrm{cm}]$} & a & $191.3 \pm 7.5$ & $193.5 \pm 10.9$ & $195.8 \pm 8.4$ & $197.9 \pm 9.3$ & $202.5 \pm 8.7$ \\
\hline & $\mathrm{b}$ & $178.0-205.4$ & $175.0-216.0$ & $175.7-209.4$ & $182.9-213.1$ & $185.5-216.5$ \\
\hline & c & 190.8 & 194.8 & 194.9 & 196.1 & 200.9 \\
\hline \multirow{3}{*}{ Sitting height [cm] } & a & $94.2 \pm 4.6$ \#\# & $94.9 \pm 4.0^{\wedge}$ & $98.3 \pm 3.4^{\# \wedge}$ & $100.3 \pm 4.4$ & $101.5 \pm 3.0$ \\
\hline & $\mathrm{b}$ & $82.8-100.7$ & $87.3-101.4$ & $92.8-103.4$ & $94.1-110.1$ & $98.2-108.0$ \\
\hline & c & 94.7 & 95.0 & 98.8 & 100.0 & 101.2 \\
\hline \multirow{3}{*}{$\begin{array}{l}\text { Distance to the sst } \\
\text { (suprasternale) } \\
\text { landmark [cm] }\end{array}$} & a & $152.6 \pm 6.2^{\#}$ & $153.6 \pm 8.1$ & $156.9 \pm 6.1^{\#}$ & $158.5 \pm 7.4$ & $161.8 \pm 6.1$ \\
\hline & $\mathrm{b}$ & $139.9-162.0$ & $140.5-168.2$ & $141.6-169.0$ & $148.2-173.3$ & $153.1-173.5$ \\
\hline & c & 152.7 & 155.1 & 157.1 & 157.3 & 162.4 \\
\hline \multirow{2}{*}{$\begin{array}{l}\text { Distance to the a } \\
\text { (acromion) }\end{array}$} & a & $154.5 \pm 6.2$ & $154.5 \pm 8.5$ & $158.0 \pm 5.9$ & $159.9 \pm 7.6$ & $164.1 \pm 6.4$ \\
\hline & $\mathrm{b}$ & $142.6-165.9$ & $140.8-172.0$ & $142.5-170.0$ & $150-174.4$ & $154.9-176.4$ \\
\hline landmark [cm] & c & 153.9 & 155.2 & 157.7 & 158.5 & 164.4 \\
\hline \multirow{3}{*}{$\begin{array}{l}\text { Distance to the da } \\
\text { III (dactylion III) } \\
\text { landmark [cm] }\end{array}$} & a & $71.0 \pm 3.7$ & $70.5 \pm 4.1$ & $72.4 \pm 3.4$ & $72.9 \pm 3.9+$ & $75.9 \pm 2.8 \dagger$ \\
\hline & $\mathrm{b}$ & $62.7-77.1$ & $64.7-80.6$ & $66.6-80.0$ & $67.2-80.5$ & $71.0-80.0$ \\
\hline & c & 71.5 & 69.7 & 73.0 & 71.5 & 75.6 \\
\hline \multirow{3}{*}{$\begin{array}{l}\text { Distance to the ti } \\
\text { (tibiale) landmark } \\
\text { [cm] }\end{array}$} & a & $52.0 \pm 2.3$ & $52.7 \pm 3.5$ & $53.7 \pm 3.3$ & $51.5 \pm 2.7 \mathrm{tt}$ & $54.3 \pm 2.4+t$ \\
\hline & $\mathrm{b}$ & $46.7-56.1$ & $47.5-63.2$ & $47.5-60.2$ & $47.6-56.0$ & $50.1-57.9$ \\
\hline & c & 51.5 & 52.6 & 53.5 & 51.5 & 54.2 \\
\hline
\end{tabular}

Significant differences between the $U-14$ and $U-16$ teams: ${ }^{*} p<0.05,{ }^{\# \#} p<0.01$

Significant differences between the U-15 and U-16 teams: ${ }^{\wedge} p<0.05, \wedge \wedge \wedge p<0.001$

Significant differences between the U-18 and U-20 teams: $+p<0.05,++p<0.01$ 
Table 2

Body widths and depths of the players in each age category considered in the study.

\begin{tabular}{|c|c|c|c|c|c|c|}
\hline Variables & & $\begin{array}{c}\mathrm{U}-14 \\
(n=32)\end{array}$ & $\begin{array}{c}\mathrm{U}-15 \\
(n=24)\end{array}$ & $\begin{array}{c}\mathrm{U}-16 \\
(n=21)\end{array}$ & $\begin{array}{c}\mathrm{U}-18 \\
(n=17)\end{array}$ & $\begin{array}{c}\mathrm{U}-20 \\
(n=15)\end{array}$ \\
\hline \multirow{3}{*}{$\begin{array}{l}\text { Shoulder width } \\
\text { [cm] }\end{array}$} & $\mathrm{a}$ & $39.9 \pm 2.0 \#$ & $40.6 \pm 2.4^{\wedge}$ & $41.9 \pm 1.7$ \#\# & $42.3 \pm 1.7$ & $43.3 \pm 2.0$ \\
\hline & $\mathrm{b}$ & $35.0-43.1$ & $37.0-45.0$ & $38.7-44.1$ & $39.3-46.0$ & $38.5-45.6$ \\
\hline & C & 40.3 & 40.7 & 42.0 & 42.0 & 43.7 \\
\hline \multirow{3}{*}{ Chest width [cm] } & $\mathrm{a}$ & $28.6 \pm 1.7 * \#$ & $29.7 \pm 2.1^{*}$ & $30.1 \pm 1.8$ \#\# & $30.3 \pm 1.5+$ & $31.8 \pm 2.2+$ \\
\hline & $b$ & $25.5-32.6$ & $24.3-33.0$ & $26.7-34.0$ & $28.0-33.5$ & $28.0-34.5$ \\
\hline & c & 28.5 & 30.3 & 30.1 & 30.0 & 33.0 \\
\hline \multirow{3}{*}{ Chest depth [cm] } & $\mathrm{a}$ & $19.6 \pm 1.8 \#$ & $20.1 \pm 2.1$ & $21.1 \pm 1.4 \#$ & $20.9 \pm 2.3$ & $21.3 \pm 1.7$ \\
\hline & $\mathrm{b}$ & $16.6-25.1$ & $16.8-25.0$ & $18.1-23.7$ & $18.5-27.0$ & $19.2-25.4$ \\
\hline & c & 19.2 & 19.8 & 21.4 & 20.5 & 20.7 \\
\hline \multirow{3}{*}{ Pelvic width $[\mathrm{cm}]$} & $\mathrm{a}$ & $29.4 \pm 2.2$ & $29.7 \pm 2.0$ & $29.2 \pm 1.6$ & $30.4 \pm 2.1$ & $30.7 \pm 1.6$ \\
\hline & $\mathrm{b}$ & $26.0-36.0$ & $24.5-33.5$ & $26.0-31.8$ & $26.4-33.8$ & $28.5-33.5$ \\
\hline & C & 29.0 & 30.3 & 29.2 & 30.5 & 30.4 \\
\hline \multirow{3}{*}{ Hip width [cm] } & $\mathrm{a}$ & $32.5 \pm 2.1 \#$ & $33.4 \pm 2.0$ & $34.0 \pm 1.4 \#$ & $33.8 \pm 1.7$ & $34.6 \pm 2.2$ \\
\hline & $b$ & $28.5-37.8$ & $29.5-37.0$ & $29.7-35.5$ & $31.5-37.0$ & $30.0-38.4$ \\
\hline & c & 32.6 & 33.7 & 34.2 & 34.0 & 35 \\
\hline \multirow{3}{*}{$\begin{array}{l}\text { Elbow breadth } \\
\text { [cm] }\end{array}$} & $\mathrm{a}$ & $7.5 \pm 0.5 *$ & $7.7 \pm 0.4 *$ & $7.6 \pm 0.4$ & $7.7 \pm 0.6$ & $7.8 \pm 0.6$ \\
\hline & $b$ & $6.5-8.6$ & $7.0-8.5$ & $6.5-8.3$ & $6.8-8.9$ & $7.0-8.9$ \\
\hline & C & 7.5 & 7.7 & 7.7 & 7.7 & 7.7 \\
\hline \multirow{3}{*}{$\begin{array}{l}\text { Knee breadth } \\
\text { [cm] }\end{array}$} & $\mathrm{a}$ & $9.9 \pm 0.6$ & $10.0 \pm 0.5$ & $9.9 \pm 0.5$ & $10.1 \pm 0.6$ & $10.1 \pm 0.6$ \\
\hline & $\mathrm{b}$ & $8.5-12.0$ & $8.9-10.8$ & $8.5-11.0$ & $8.8-11.1$ & $9.1-11.2$ \\
\hline & $\mathrm{C}$ & 9.8 & 10.1 & 10.0 & 10.0 & 9.9 \\
\hline \multirow{3}{*}{$\begin{array}{l}\text { Wrist breadth } \\
\text { [cm] }\end{array}$} & $\mathrm{a}$ & $5.7 \pm 0.3 \#$ & $5.9 \pm 0.3$ & $5.9 \pm 0.3 \#$ & $5.8 \pm 0.4$ & $5.9 \pm 0.3$ \\
\hline & $b$ & $5.2-6.5$ & $5.3-6.4$ & $5.5-6.6$ & $5.3-6.5$ & $5.5-6.8$ \\
\hline & c & 5.7 & 5.8 & 6.0 & 5.7 & 5.8 \\
\hline \multirow{3}{*}{ Palm breadth $[\mathrm{cm}]$} & $\mathrm{a}$ & $10.2 \pm 0.5$ & $10.3 \pm 0.5$ & $10.5 \pm 0.6$ & $10.8 \pm 0.4$ & $10.8 \pm 0.5$ \\
\hline & b & $9.2-11.5$ & $9.5-11.5$ & $9.0-11.5$ & $10.3-11.5$ & $10.3-11.7$ \\
\hline & c & 10.3 & 10.4 & 10.5 & 10.8 & 10.7 \\
\hline
\end{tabular}

Significant differences between the U-14 and U-15 teams: ${ }^{*} p<0.05$

Significant differences between the U-14 and U-16 teams: ${ }^{*} p<0.05,{ }^{\# \#} p<0.01$

Significant differences between the $U-15$ and $U-16$ teams: ${ }^{\wedge} p<0.05$

Significant differences between the U-18 and U-20 teams: $+p<0.05$ 
Table 3

Circumference values of players in each age category of the Polish national basketball teams.

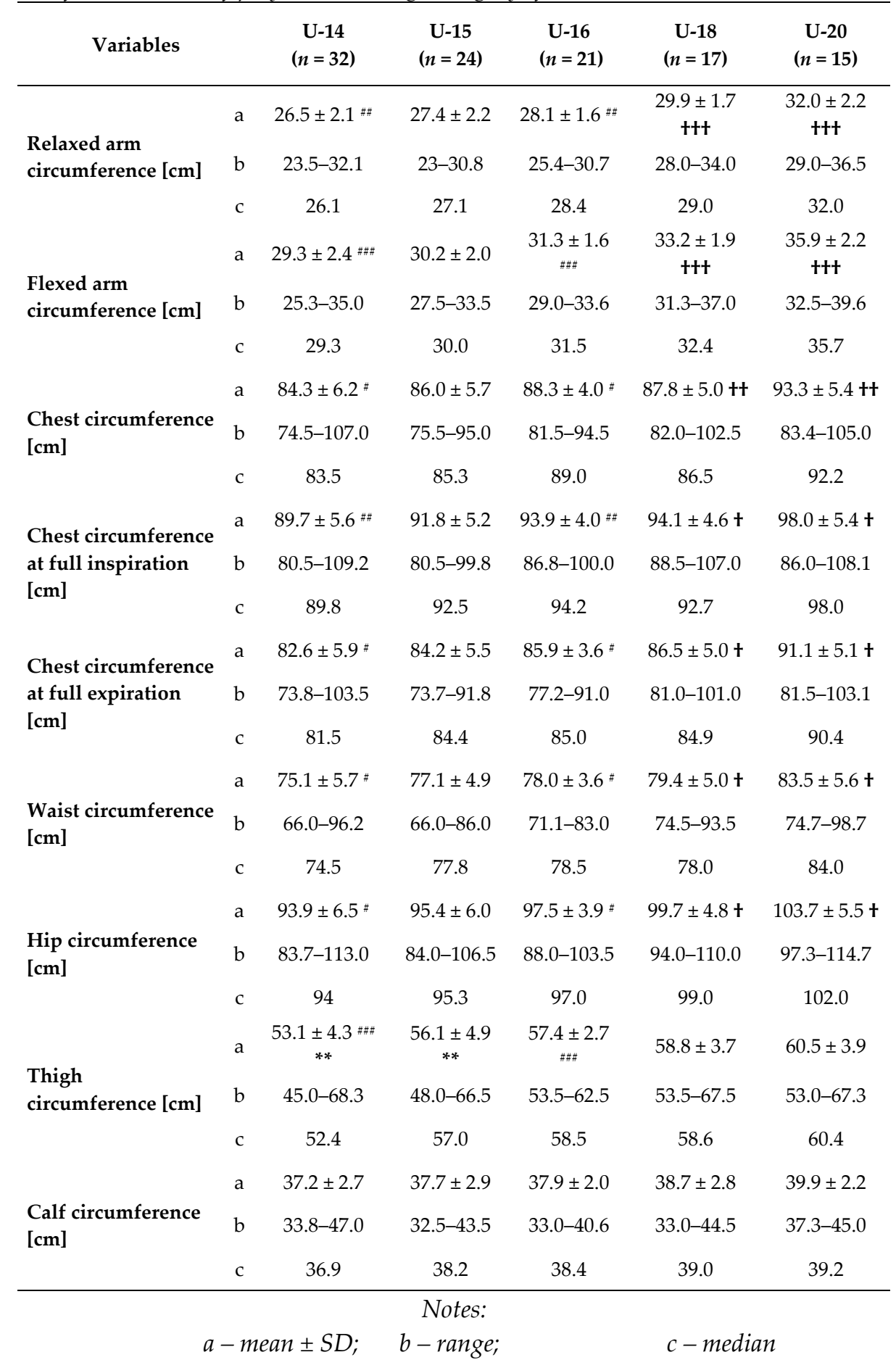

Significant differences between the U-14 and U-15 teams: ${ }^{* *} p<0.01$

Significant differences between the U-14 and U-16 teams: $p<0.05$, \# $p<0.01$, \#\#\# $p<0.001$ Significant differences between the U-18 and U-20 teams: $+p<0.05,++p<0.01,+++p<0.001$ 
Table 4

Anthropometric differences by playing position.

\begin{tabular}{|c|c|c|c|c|}
\hline \multirow{2}{*}{ Position } & \multicolumn{2}{|c|}{ Stature } & \multicolumn{2}{|c|}{ Arm span } \\
\hline & $\begin{array}{l}\text { Mean } \\
(\mathrm{cm})\end{array}$ & CI & $\begin{array}{l}\text { Mean } \\
(\mathrm{cm})\end{array}$ & $\mathrm{CI}$ \\
\hline $\begin{array}{l}\text { Point } \\
\text { guard }\end{array}$ & $182.8^{*}$ & $\begin{array}{c}181- \\
183\end{array}$ & $186.8^{*}$ & $185-189$ \\
\hline $\begin{array}{c}\text { Shooting } \\
\text { guard }\end{array}$ & $187.4^{*}$ & $\begin{array}{c}186- \\
188\end{array}$ & $192.2^{*}$ & $190-194$ \\
\hline $\begin{array}{l}\text { Small } \\
\text { forward }\end{array}$ & $191.4^{*}$ & $\begin{array}{c}190- \\
193\end{array}$ & $196.7^{*}$ & $195-199$ \\
\hline $\begin{array}{l}\text { Power } \\
\text { forward }\end{array}$ & $194.8^{*}$ & $\begin{array}{c}193- \\
196\end{array}$ & $201.7^{*}$ & $199-204$ \\
\hline Center & 199.4 * & $\begin{array}{c}198- \\
200\end{array}$ & 204.5 * & $202-207$ \\
\hline
\end{tabular}

${ }^{*}$ Different from all other positions by post hoc test, $C I=$ confidence interval

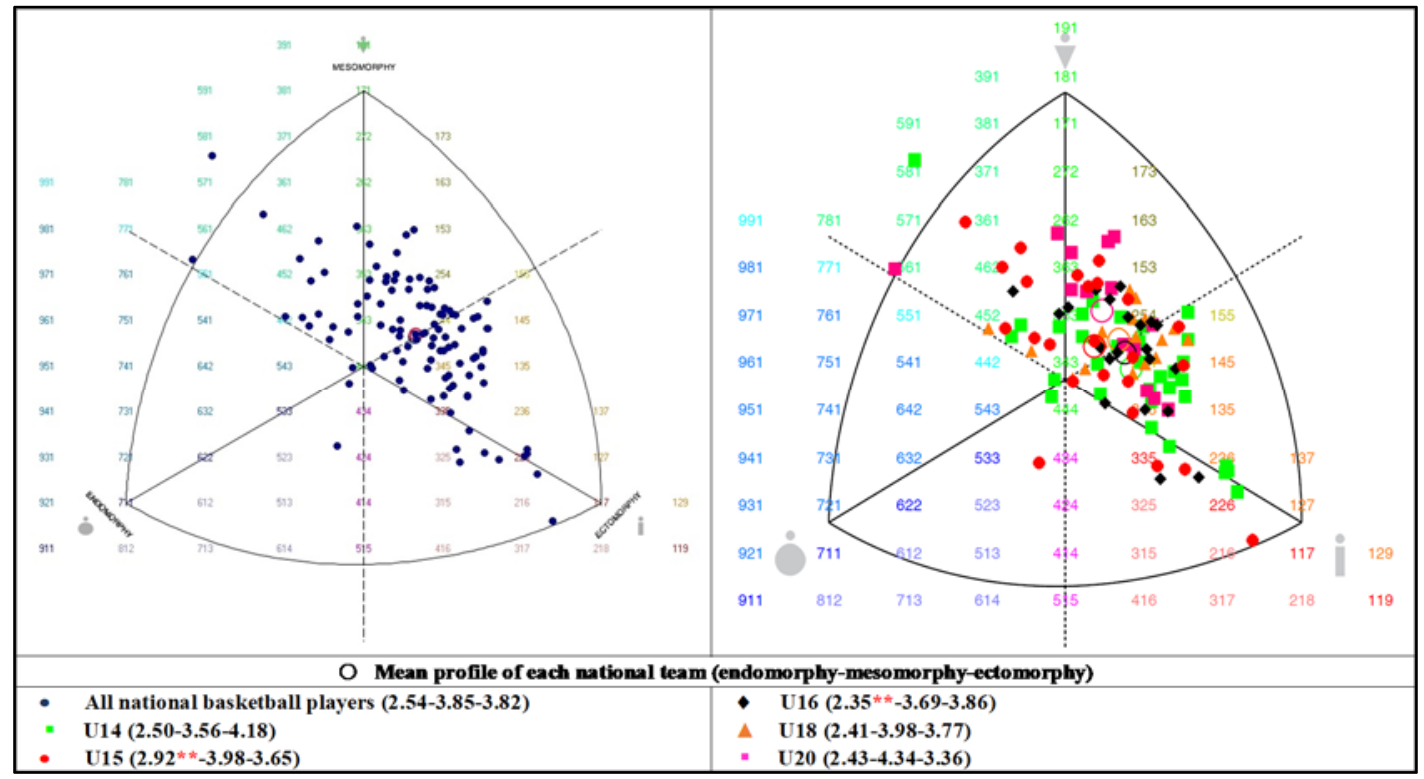

Figure 1

Somatochart of the whole sample population and each national team member.

Significant differences between the U-15 and U-16 teams (endomorphy component): ${ }^{*} \boldsymbol{p}<\mathbf{0 . 0 5}$ 


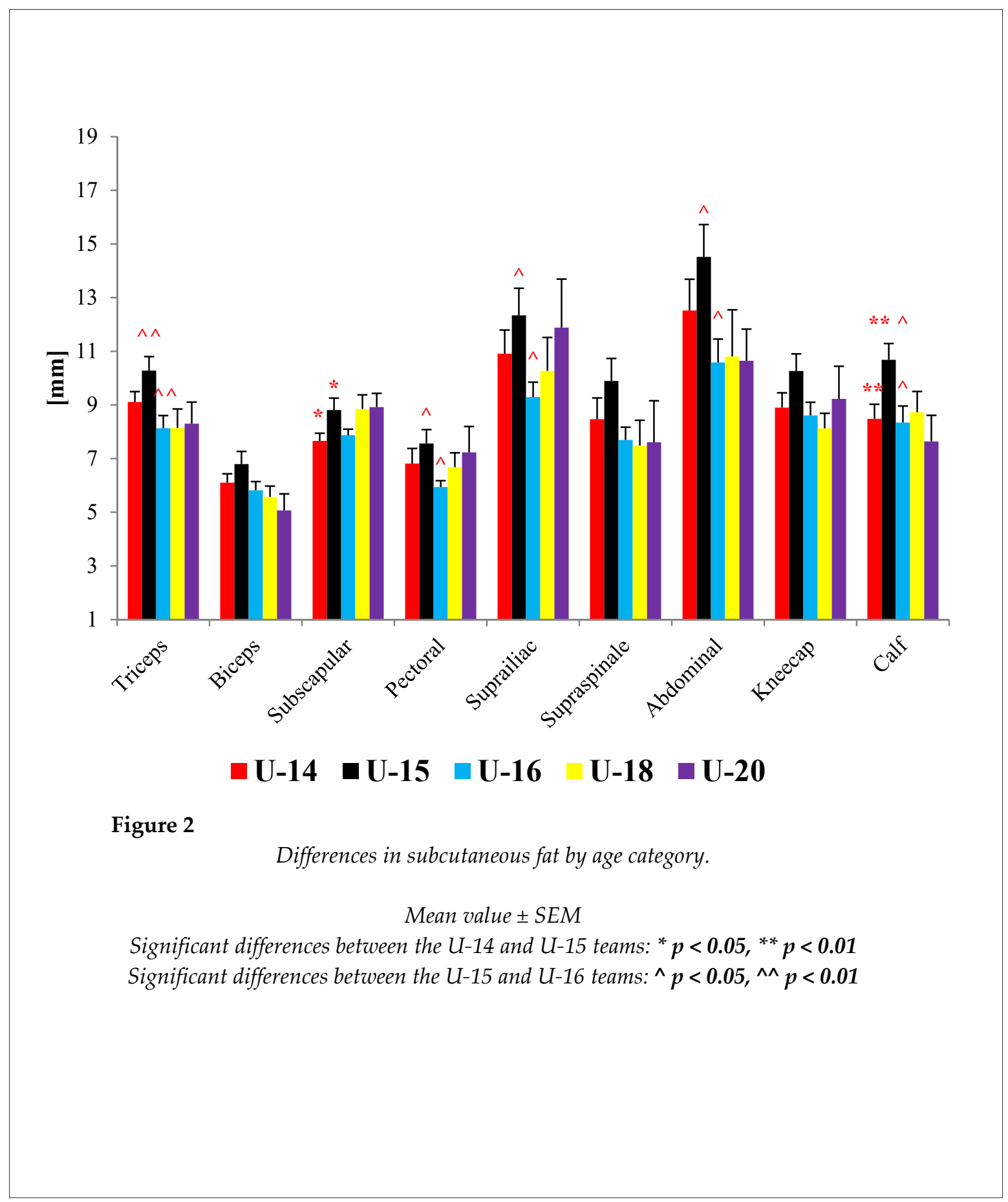

This is especially true for players in the center or power forward positions, where long measurements and an appropriate ratio of tissue components are required. There are situations where young players are chosen too early to play in positions that they do not have a chance to play in when they are older during professional competitions. Therefore, it is advisable to ensure comprehensive training for players, and the selection for each position should take place after their growth has ended.

A comprehensive analysis of the anthropometric characteristics and body build profiles of players of youth basketball teams showed differences between players from the younger teams (U-14, U-15 and U-16) and players from the older teams (U-18 and U-20); length, width and circumference measurements and body 
masses ranged from 3.6 to $9.3 \%$, and subcutaneous fat measured through skinfold thickness tests ranged from 14.3 to $33.7 \%$. The somatic feature measurements increased linearly with age. When these measurements were compared to the results obtained for players from other national teams (Jakovljević et al., 2011; Silva et al., 2012; Vaquera et al., 2015) and professional teams (Gonzalo-Skok et al., 2015; Petrovic et al., 2013;), no significant differences were found in the levels of basic body height and mass characteristics of players from the U-14 and U-15 teams. A similar body height was noted in players from the U-14 and U-15 teams in comparison to their peers from Serbia and Spain (with differences of $0.3 \%,+0.6 \mathrm{~cm}$ and $0.5 \%,-0.9 \mathrm{~cm}$, respectively). Similar relationships were observed in U-20 teams from Poland and from Spain $(0.2 \%$, $-0.4 \mathrm{~cm})$. Conversely, the study observed differences in body height of players from the U16 and U-18 Poland national teams in comparison with the height of U-16 players from Great Britain $(4.4 \%,+8.6 \mathrm{~cm})$ and Portugal $(1.6 \%,-3.2 \mathrm{~cm})$ and $\mathrm{U}-18$ players from Spain $(2.5 \%,-5 \mathrm{~cm})$.

This may result from an inappropriate recruitment and selection process, i.e., an incorrect prediction of adult body height. In the first two age categories (U14 and U15), Polish players do not stand out in terms of the basic anthropometric features from their peers from countries in which coaching is considered at the highest level, but an inhibition of individual development is observed in U16-U18 categories at the level that does not predict success in basketball. Due to incorrect body height predictions, sports performance is also at a low level. Aptitudes for practising other sports (with a simultaneous decision to change the sport) are also observed. Furthermore, new players appear in the youth national team with the oldest players (U20), and after the process of growth, these players have aptitudes in terms of basic anthropometric features, but they were not included at the early stages of the selection process.

A comparison of body mass between the Polish and Serbian players revealed that measurements obtained for players from the U-14 Poland national team were greater by $6.7 \%$ (Jakovljević et al., 2011). Similarly, for the U-15 category, body mass measurements of Polish players were greater than those of Spanish players (with values higher by 5.7\%), and for the U-16 age category, body mass measurements of Polish players were greater than those of Portuguese players (with values higher by $3.1 \%$ ) and British players (with values higher by 6.8\%) (GonzaloSkok et al., 2015; Petrovic et al., 2013; Silva et al., 2012). On the other hand, body mass measurements of U-18 Polish basketball players were lower than those of players from Spain by $9.7 \%$, but this measurement was similar among U20 players (Vaquera et al., 2015). The body mass changes and characteristics of players at individual stages of ontogenesis and sports training may show high interindividual variability. Differences in body mass between players of the same age category may be due to population differences.

In addition to body mass and height, anthropological analyses of elite basketball players should also take into consideration the circumference and width measurements, as well as the skinfold thicknesses, which provide additional information about a strong body build and adequate body musculature (Sallet et al., 2005; Sisodiya and Yadaf, 2010). In a study of 55 professional basketball players from Bosnia (age: $19.09 \pm 3.13$ years; body height: $189.13 \pm 8.30 \mathrm{~cm}$; body mass: $83.42 \pm 12.48 \mathrm{~kg}$ ), researchers described the distributions of subcutaneous fat tissue and reported skinfold thicknesses ranging from 10.07 to $17.91 \mathrm{~mm}$. Regardless of the player's on-court position, the highest amount of subcutaneous fat was found in the central part of the body trunk (abdominal skinfold), and the lowest amount was observed in the triceps skinfold (Pojskic et al., 2014). In our study, regardless of the basketball players' age, the lowest levels of subcutaneous fat were found in the biceps skinfold (ranging from 5.1 to $6.8 \mathrm{~mm}$ ) and the pectoral skinfold (5.9-7.2 $\mathrm{mm})$, while the highest levels were documented in similar body parts as in the study by Pojskic et al. (2014), i.e., in the abdominal skinfold (10.6-14.5 mm) and suprailiac skinfold $(9.3-11.9 \mathrm{~mm})$. The observed distribution of subcutaneous fat is characteristic for individuals who play a sport in which highintensity, dynamic work is performed by the upper limbs, and the largest accumulation of subcutaneous fat tissue is commonly observed in the central part of the body (body trunk). The distribution of body fat changes with subsequent 
stages of sports training. In the youngest athletes, total body fat may constitute a greater proportion of the total body mass, and with the processes of growth and intensive sports training in the male population, muscle mass increases, whereas the body fat decreases (Malina and Geithner, 2011).

The present study revealed a significant similarity between the distribution of subcutaneous fat in Polish players and anthropometric characteristics of Spanish professional basketball players, who also, regardless of age, displayed the lowest amount of subcutaneous fat in the biceps skinfold and the highest amount in the abdominal skinfold (Vaquera et al., 2015). The study on elite Spanish basketball players revealed that youngest players had the lowest amounts of subcutaneous fat and that the amount of subcutaneous fat increased with age. On the other hand, among the best Polish players, the highest amount of subcutaneous fat was observed in U-15 national team players, and this amount was greater than that of both the younger players from the U-14 category and the older players from U-16 to U-20 national teams, regardless of which skinfold area was measured.

The thinness of the biceps skinfolds of basketball players is due to the specificity of the sport. The upper limbs perform dynamic work during games. Therefore, in the training process, athletes support themselves with strength training to increase the proportion of muscle mass to the total body mass. A large proportion of muscle mass to body mass contributes to improved playing efficiency during a game (Santos and Janeira, 2008). Muscular and efficient upper limbs can contribute to more effective ball handling (throwing, passing, dribbling, and playing games with a ball), more effective plays when in contact with the opponent, and stronger screens.

The evolution of rules, techniques and tactics of play, which are fundamental parts of basketball training, has led to greater physiological and anthropometric differences between players from different age categories (Cormery et al., 2008; Drinkwater et al., 2008). Analysing these differences may help coaches predict the fitness levels and the physical capabilities of individual players. The multitasking activities performed by players during a basketball game require exceptional skills, and only those players with great abilities can achieve a high level of success. However, anthropometric characteristics including length, width and circumference measurements, as well as skinfold thicknesses, constitute a major factor in the selection of basketball players, and these characteristics can consequently determine the final success or failure of a team.

\section{Conclusions}

The present study demonstrated that the anthropometric evaluation of body builds and body profiles may be a key tool for the selection and recruitment of players for basketball teams and, in older categories, for the appropriate selection of their positions on the court. Monitoring an individual's somatic build is important for the proper selection of players in each age category, and this process becomes especially important during the transition from the junior stage to professional basketball.

The second aim of our study was to estimate key anthropometric variables for the position selection of national players. Our study provides clear evidence that the positions listed in descending order according to players' body height and arm span are centers, forwards and guards. These results are evident not only with respect to players' calendar ages, but also with respect to players' maturity offsets. We found other differences in positions, but they did not increase linearly with all observed changes; the other results can be found at https://onpecha.cz/basket/national.html. Since these results are in accordance with our previous findings (Gryko et al., 2018), we can recommend body height and arm span as useful variables for the selection of talented players for specific playing positions.

It should be emphasised that further research on this subject is required and that such studies should be expanded to include anthropometric analyses of the five different oncourt positions and requirements related to particular positions, especially in the junior categories (U-18 and U-20). Results of this study may have a significant impact on the success of teams in basketball competitions at the professional level. 


\section{Acknowledgements}

The authors would like to thank players and coaches from Polish national teams for their participation in the study. We would also like to thank the Polish Basketball Federation for their assistance in this study. The study was supported by the Józef Piłsudski University of Physical Education in Warsaw as part of its statutory activities (DS-279) and Charles University grant UNCE/HUM/032.

\section{References}

Abdelkrim BN, Chaouachi A, Chamari K, Chtara M, Castagna C. Positional role and competitive-level differences in elite level men's basketball players. J Strength Cond Res, 2010; 24: 1346-55 doi: 10.1519/JSC.0b013e3181cf7510

Bayios IA, Bergeles NK, Apostolidis NG, Noutsos KS, Koskolou MD. Anthropometric, body composition and somatotype differences of Greek elite female basketball, volleyball and handball players. J Sport Med Phys Fit, 2006; 46: 271-280

Carter JL, Heath BH. Somatotyping: Development and Applications. Cambridge University Press, Cambridge, UK; 1990

Cormery B, Marcil M, Bouvard M. Rule change incidence on physiological characteristics of elite basketball players: a 10-year-period investigation. Brit J Sport Med, 2008; 42(1): 25-30 doi:10.1136/bjsm.2006.033316

Crisafulli A, Melis F, Tocco F, Laconi P, Lai C, Conçu A. External mechanical work versus the oxidative energy consumption ratio during a basketball field test. J Sport Med Phys Fit, 2002; 42(4): 409-417

Czuba M, Zając A, Maszczyk A, Roczniok R, Poprzęcki S, Garbaciak W, Zając T. The effects of high intensity interval training in normobaric hypoxia on aerobic capacity in basketball players. J Hum Kinet, 2013; 39: 103-114 doi: 10.2478/hukin-2013-0073

Drinkwater EJ, Pyne DB, McKenna MJ. Design and interpretation of anthropometric and fitness testing of basketball players. Sports Med, 2008; 38(7): 565-578

Drinkwater EJ, Pyne DB, McKenna MJ, Hopkins WG, Hunt PH. Modelling age and secular differences in fitness between basketball players. J Sport Sci, 2007; 25(8): 869-878

Erčulj F, Štrumbelj E. Basketball shot types and shot success in different levels of competitive basketball. PLoS One, 2015; 10(6): e0128885 doi:10.1371/journal.pone.0128885

Escalante Y, Saavedra JM, García-Hermoso A. Game-related statistics in basketball by player position and final game score differences in the European Basketball Championship 2007. Fit Perf J, 2010; 9(2): 5056 doi:10.3900/fpj.9.2.50.p

Fruchart E, Pâques P, Mullet E. Decision-making in basketball and handball games: a developmental perspective. Eur Rev of Appl Psychol, 2010; 60(1): 27-34

García J, Ibáñez SJ, De Santos RM, Leite N, Sampaio J. Identifying basketball performance indicators in regular season and playoff games. J Hum Kinet, 2013; 36: 163-170

Gerodimos V, Manou V, Kellis E, Kellis S. Body composition characteristics of elite basketball players. J Hum Movement Stud, 2005; 49: 115-126

Gomes JH, Chaves RG, Evangelista A, Charro MA, Bocalini DS, Figueira Junior AJ. Relationship between anthropometrics, physical performance and game statistics in young elite basketball players. Rev Bras Cienc Mov, 2015; 23(2): 66-73

Gonzalo-Skok O, Serna J, Rhea MR, Marín PJ. Relationships between functional movement tests and performance tests in young elite male basketball players. Int J Sports Phys Ther, 2015; 10(5): 628-638 PMC4595916

Gryko K, Kopiczko A, Mikołajec K, Stasny P, Musalek M. Anthropometric variables and somatotype of young and professional male basketball players. Sports, 2018; 6(1): 9 https://doi.org/10.3390/sports6010009

Grissom RJ, Kim JJ. Effect sizes for research: Univariate and multivariate applications, second edition. Routledge; 2012 
Hoare DG. Predicting success in junior elite basketball players - the contribution of anthropometric and physiological attributes. J Sci Med in Sport, 2000; 3(4): 391-405

Jakovljević S, Pajić Z, Gardašević B, Karalejić M, Mandić R. Influence of anthropometric characteristics on speed abilities of 14 year old elite male basketball players. Journal of Physical Education and Sport, 2011; 11(2): 221-225

Kica H. The impact of certain anthropometric and motor indicators on the efficiency of scoring points in a basketball game of 15 year old students. Research in Kinesiology, 2012; 40(2): 231-236

Koley S, Singh J. Anthropometric and physiological characteristics of Indian Interuniversity basketball players. Journal of Physical Education and Sport, 2010; 28(3): 70-76

Kollos C, Tache S. Anthropometric indicators and aerobic exercise capacity in young basketball players. Palestrica of the third millennium - Civilization and Sport, 2013; 14(3): 195-199

Kostopoulos N. Anthropometric and fitness profiles of young basketball players according to their playing position and time. Journal of Physical Education and Sport, 2015; 15(1): 82-87 doi:10.7752/jpes.2015.01014

Malina RM, Cumming SP, Kontos AP, Eisenmann JC, Ribeiro, B, Aroso, J. Maturity associated variation in sport-specific skills of youth soccer players aged 13-15 years. J Sports Sci, 2005; 23: 515-522

Malina RM, Geithner CA. Body Composition of Young Athletes. Am J Lifestyle Med, 2011; 5(3): 262-278. doi: $10.1177 / 1559827610392493$

Marfell-Jones MJ, Stewart AD, De Ridder JH. International standards for anthropometric assessment. Wellington, New Zealand: International Society for the Advancement of Kinanthropometry; 2012

Meckell Y, Casorla T, Eliakim A. The influence of basketball dribbling on repeated sprints. International Journal of Coaching Science, 2009; 3(2): 43-56

Mikolajec K, Waskiewicz Z, Maszczyk A, Bacik B, Kurek P, Zając, A. Effects of stretching and strength exercises on speed and power abilities in male basketball players. Isokinet Exerc Sci, 2012; 20(1): 61-69

Mirwald RL, Baxter-Jones AD, Bailey DA, Beunen, GP. An assessment of maturity from anthropometric measurements. Med Sci Sports Exerc, 2002; 34: 689-694

Muratovic A, Vujovic D, Hadzic R. Comparative study of anthropometric measurement and body composition between elite handball and basketball players. Montenegrin Journal of Sports Science and Medicine, 2014; 3(2): 19-22

Ochoa MPY, Hall LJA, Alarcón MEI, Arráyales MEM, Sánchez LR. Somatotype profile and body composition of players from the Mexican professional basketball league. Int J Morphol, 2014; 32(3): 1032-1035

Ostojic S, Mazic S, Dikic N. Profiling in basketball: physical and physiological characteristics of elite players. J Strength Cond Res, 2006; 20(4): 740-744 doi:10.1519/R-15944.1

Petrovic M, Ramos J, Šolaja M, Golik-Peric D, Obradovic B. Influence of anthropometric characteristics on jumping performance in young basketball players in the British Basketball League. Sport Scientific \& Practical Aspects, 2013; 10(2): 31-34

Pojskic H, Separovic V, Muratovic M, Uzicanin E. Morphological differences of elite Bosnian basketball players according to team position. Int J Morphol, 2014; 32(2): 690-694 doi: 10.4067/S071795022014000200051

Sallet P, Perrier D, Ferret JM, Vitelli V, Baverel G. Physiological differences in professional basketball players as a function of playing position and level of play. J Sport Med Phys Fit, 2005; 45(3): 291-294

Santos EJ, Janeira MA. Effects of complex training on explosive strength in adolescent male basketball players. J Strength Cond Res, 2008; 22(3): 903-9 doi: 10.1519/JSC.0b013e31816a59f2

Silva AM, Santos DA, Matias CN, Rocha PM, Petroski EL, Minderico CS, Sardinha LB. Changes in regional body composition explain increases in energy expenditure in elite junior basketball players over the season. Eur J Appl Physiol, 2012; 112(7): 2727-37 doi, 10.1007/s00421-011-2221-8

Sisodiya A, Yadaf M. Relationship of anthropometric variables to basketball playing ability. Journal of Advances in Developmental Research, 2010; 1(2): 191-194

Torres-Unda J, Zarrazquin I, Gravina L, Zubero J, Seco J, Gil SM, Gi, J, Irazusta J. Basketball performance is 
related to maturity and relative age in elite adolescent players. J Strength Cond Res, 2016; 30(5): 13251332

Vaquera A, Santos S, Villa JG, Morante JC, García-Tormo V. Anthropometric characteristics of Spanish professional basketball players. J Hum Kinet, 2015; 46: 99-106 doi: 10.1515/hukin-2015-0038

World Medical Association Declaration of Helsinki: Ethical Principles for Medical Research Involving Human Subjects. JAMA, 2013; 27;310(20): 2191-4 doi: 10.1001/jama.2013.281053. Available at: https://www.wma.net/wp-content/uploads/2016/11/DoH-Oct2013-JAMA.pdf; accessed on 15.12.2016

\section{Corresponding author:}

\section{Karol Gryko, Ph.D.}

Józef Piłsudski University of Physical Education in Warsaw

Faculty of Physical Education, Department of Athletics and Team Sport Games

Marymoncka 34

Warszawa 00-968

Poland

Tel.: + 504148465 ,

E-mail: k.gryko@awf.edu.pl 